\title{
A sesenta años de la creación del Centro Histórico y Geográfico de Soriano
}

Lucía Mariño y Guido Quintela

Universidad de la República, Uruguay

Este escrito recoge parte de una entrevista realizada el 4 de diciembre de 2017 en la sede del Centro Histórico y Geográfico de Soriano (CHGS) a Alfonso Arias, Agustín Listur, Olga Segurola y Olga Ceriani, integrantes de la institución, para realizar un repaso por su historia en ocasión de su sesenta aniversario. Tuvo lugar en el marco del proyecto "Guerra, control territorial y organización de la Provincia Oriental. Paysandú, Santo Domingo Soriano y Colonia entre 1825 y 1830”, financiado por el Programa de apoyo a la investigación estudiantil (PAIE) de la Universidad de la República, y de las actividades del grupo "Crisis revolucionaria y procesos de construcción estatal en el Río de la Plata” de la Facultad de Humanidades y Ciencias de la Educación, coordinado por Ana Frega y Nicolás Duffau.

El 27 de octubre de 1958 fue firmada el acta de fundación del Centro de Investigaciones Históricas del departamento de Soriano, como se llamó inicialmente, por el profesor Manuel Santos Pírez y un pequeño grupo de estudiantes liceales. Casi sesenta años después, el acta luce encuadrada en la sala principal del Centro Histórico y Geográfico de Soriano, ubicado en el número 618 de la calle Artigas, en la ciudad de Mercedes.

El surgimiento de esta institución, como señalan los entrevistados, se enmarca en un proceso que comenzó hacia 1950, cuando se intentó organizar un Museo Histórico en el departamento, a raíz de la posteriormente frustrada ley para la implementación de museos departamentales de 1948. Por iniciativa de un grupo de personas provenientes del ámbito jurídico, social y del profesorado del liceo departamental se creó una comisión para llevar adelante tal empresa. Dicha comisión estaba integrada por el doctor Juan Carlos Viera, quien fue fiscal; el doctor Luis Soumastre, abogado y profesor de historia; Enrique Santías, también profesor de historia; entre otras personalidades del medio. Sin embargo, comentan los miembros 
del Centro, la Intendencia Municipal de Soriano de entonces no le dedicó mucha importancia a la iniciativa.

En el departamento de Soriano, las preocupaciones por conocer y difundir temas históricos se remontan a fines del siglo XIX. Como señala el historiador Carlos Zubillaga, aunque a veces no constituían abordajes totalmente historiográficos, contribuyeron a "visualizar el Departamento de Soriano como una realidad específica, no diluible en una identidad nacional homogeneizada" ${ }^{1}$. Con respecto a estas producciones con enfoques locales, el mismo autor destaca su importancia, ya que la Historia en Uruguay siempre ha tenido una fuerte impronta centralista que distorsiona la comprensión "cabal” del pasado.

Debido a la demanda constante desde la dirección del liceo departamental, Instituto "José María Campos", y sobre la base de los antecedentes ya señalados, en mayo de 1952 se creó por decreto municipal la Junta Regional de Historia, presidida por el entonces director del liceo, Gregorio Cardozo. Esta Junta rápidamente desplegó una actividad constante y contactó con el Instituto de Investigaciones Históricas de la Facultad de Humanidades en Montevideo, con quienes llegaron a plantear la idea de publicar algún tipo de producto historiográfico en conjunto².

En ocasión del vigésimo aniversario del Centro, en el número 21 de la Revista Histórica de Soriano el profesor Cardozo resalta también el apoyo brindado por el Instituto Histórico y Geográfico del Uruguay, que nombró a los integrantes de la Junta Regional como miembros correspondientes³.

Asimismo, Manuel Santos Pírez, en ocasión de los festejos de los veinticinco años del Centro, aporta datos sobre su fundación. Señala que en agosto de 1958 Telésforo Book, entonces alumno del liceo, escribió una carta al director del diario Acción de Mercedes bajo el seudónimo "Estudiante", para sensibilizar acerca de la

1 ZUBILLAGA, Carlos, Historia e historiadores en el Uruguay del siglo XX, Montevideo, FHCE, 2002, pp. 275-276. Señala la existencia de un trabajo de 1884 del médico gallego radicado en Mercedes, Serafín Rivas Rodríguez titulado Nociones sobre el Departamento de Soriano; un trabajo de Mariano B. Berro de 1912, La escuela antigua en Soriano y otro del año siguiente, del escribano Eusebio E. Giménez, Recuerdos del terruño. 2 Ibídem, p. 276.

3 "Del Miembro Correspondiente en Montevideo, ex Director del Instituto 'José M. Campos' de Mercedes, historiador Prof. Gregorio Cardozo”, en Revista Histórica de Soriano, N²1, Mercedes, octubre 1978, pp. 1011. Véase también ZUBILLAGA, Carlos, ob. cit., p. 277, nota al pie 806. 
importancia de crear un "Centro Regional de Historia". Allí mencionaba que la iniciativa circulaba desde el año anterior, esbozando algunas de las finalidades que podía tener ese emprendimiento4. El liceo, desde la dirección, los docentes y los estudiantes generaron el espacio para el surgimiento del Centro. Según consta en el acta, el grupo inicial estaba conformado por el profesor Manuel Santos Pírez, Heber Luzardo, Enrique Prado, Darío Prunell, Pedro Ramón Banega y Telésforo Book. Su principal cometido sería "brega[r] por hacer conocer esa ciencia [la Historia] en lo que respecta a hechos, personajes, costumbres, etc., de nuestro departamento [Soriano]"5.

A este grupo inicial se incorporó inmediatamente el profesor Washington Lockhart, un profesor de matemáticas oriundo de Montevideo, pero radicado en Mercedes, quién también pasó a dirigirlo ${ }^{6}$. Según el escribano Alfonso Arias, Lockhart tenía una personalidad especial que lo llevó a ser parte de la comisión directiva rápidamente. A su vez, Zubillaga agrega que éste confirió al Centro "un dinamismo realizador" que le permitió materializar la edición de una revista especializada, como la Revista Histórica de Soriano -de la cual Lockhart fue redactor responsable varios años- que constituyó por décadas "un emprendimiento sin parangón en el país”7.

El primer número de esta revista apareció el 31 de agosto de 1960, apenas dos años después de la creación del Centro. En sus primeras páginas, el grupo redactor conformado por Lockhart, Santos Pírez y Book, expresa los propósitos de la revista y del Centro. Eran conscientes de la gran tarea que significaba este emprendimiento y por ello el criterio a seguir de forma "inalterable", era la "verdad" del documento, manteniendo un "absoluto desperjuicio [sic], tocante a divisas y tendencias":

"Porque, -repetimos- no es para evadirnos del presente ni de su afanoso bregar por un futuro mejor que volvemos la vida hacia el pasado, sino, al contrario, por extraer de ese

\footnotetext{
4 SANTOS PÍREZ, Manuel, “Como surgió el 'Centro Histórico y Geográfico de Soriano””, Revista Histórica de Soriano, No 25, Mercedes, octubre de 1983, p. 1. La carta está fechada el 12 de agosto de 1958.

5 Ibídem, p. 2. Acta constitutiva del Centro de Investigaciones Históricas de Soriano, 27 de octubre de 1958.

6 Lockhart aparece como integrante (vicepresidente) de la primera comisión directiva del Centro, el 3 de noviembre de 1958. Esta se completaba con el profesor Manuel Santos Pírez (presidente), Darío Prunell (secretario), Heber Luzardo (tesorero), Telésforo Book (bibliotecario), Pedro Ramón Banega y Enrique Prado (Vocales). SANTOS PÍREZ, Manuel, ob. cit., p. 3.

7 ZUBILLAGA, Carlos, ob. cit., p. 277.
} 
pasado lecciones que puedan sernos de provecho y para vivificar así esas zonas del alma popular que una indiferencia perniciosa suele dejar sin asistencia"

La Revista Histórica de Soriano, que cuenta con 43 números editados hasta diciembre de 2012 (para el sesenta aniversario se está preparando un nuevo número, que saldrá en setiembre/octubre de 2018)99, fue el principal medio para la divulgación de las investigaciones y actividades del Centro. La revista también contó con

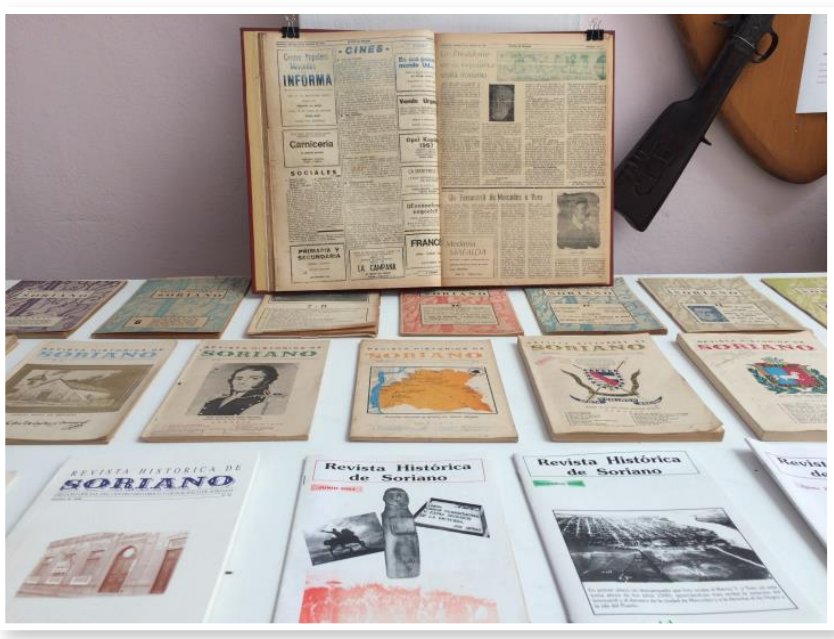

Varios números de la Revista Histórica de Soriano colaboraciones investigadores de la región y fuera de ésta.

El 8 de octubre de 1975 el Centro pasó a designarse Centro Histórico y Geográfico de Soriano ${ }^{10}$. A su vez, integraron nuevos elementos y ampliaron los campos de estudio a través de subcomisiones, que incluyeron labores en ciencias naturales.

Según los entrevistados, la vinculación con la Geografía se dio gracias al profesor Eduardo Galagorri, quién además de redactor responsable de la revista, fue presidente del Centro en varios periodos. Éste entendió las ventajas de integrar la Geografía con la Historia, tanto para enriquecer el espectro de actividades del Centro, como para atraer más personas a la institución. Asimismo, señalan que actualmente Emilio Hourcade, integrante de la comisión directiva del Centro, es quien se ocupa del aspecto geográfico publicando un boletín digital titulado "Soriano fluvial”.

En lo que refiere a la sede del Centro, no siempre tuvo su ubicación actual; particularmente en los primeros años no contó con un lugar fijo donde reunirse. Alfonso Arias relata que, en sus inicios, no contaban más que con unos cuantos libros

8 "Propósitos", Revista Histórica de Soriano, № 31, Mercedes, 31 de agosto de 1960, pp. 1-2.

9 La revista dejó de editarse asiduamente dados los costos y, según los miembros del Centro, la falta de quienes pudieran realizar sus notas. En 2010 se comenzó con la publicación del Boletín Digital.

10 SANTOS PÍREZ, Manuel, “Actividades del Centro Histórico y Geográfico de Soriano”, Revista Histórica de Soriano, $\mathrm{N}^{\circ} 16$, extraordinario, Mercedes, setiembre de 1976, p. 84. 
y cajas con documentación y el liceo les proporcionaba alguna de sus salas o se reunían en los domicilios particulares de sus integrantes. Arias agrega que cuando él se integró al grupo, en la década de 1970, comenzaron a utilizar casas que estaban en alquiler, a las que podía acceder por su profesión, para tener sus reuniones. De esa forma rotaron por varios inmuebles vacíos de la ciudad hasta que estos se alquilaban. La locación donde hoy está el Centro había sido un convento de monjas que luego quedó libre y pasó a propiedad de la Curia de Mercedes. Esta habilitó al CHGS a utilizar algunos de sus salones a través de un comodato. Posteriormente, en 1988, el Centro logró comprar el inmueble a través de préstamos particulares de sus integrantes y algunas donaciones ${ }^{11}$. Mediante dos convenios con el Ministerio de Obras Públicas han logrado mejorar las instalaciones.

Actualmente, la financiación del CHGS depende casi exclusivamente de los ciento setenta socios que posee, quienes pagan una cuota mensual (en diciembre de 2017 era de 70 pesos uruguayos). A ello se le suma el apoyo de la Intendencia de Soriano, que costea un funcionario que mantiene abierto el Centro al público.

Las actividades que desarrolla comprenden un amplio espectro de intereses y de campos. En estos sesenta años se han propiciado excursiones arqueológicas; mesas redondas sobre temas de Historia económica, social, política y cultural; conferencias y presentaciones de libros de varias personalidades; espectáculos; charlas o actividades con otras instituciones, como las Jornadas Históricas con el Club Soriano de Montevideo ${ }^{12}$. Actualmente el Centro destaca entre las actividades con más alcance de los últimos años, un ciclo sobre Oficios de ayer y de hoy, realizado en 2013.

También han contribuido con la copia de documentos inéditos referidos a la historia de Soriano que se encuentran en el extranjero, clasificación de colecciones museísticas, una hemeroteca y un fondo fotográfico de más de diez mil negativos. Cuentan también con una colección numismática y otras de objetos indígenas, gauchescos y de armas de fuego y blancas, colectadas por particulares. Estas habían

\footnotetext{
11 ARIAS, Alfonso, "Proceso Dominial de Nuestra Sede Social", Revista Histórica de Soriano, $\mathrm{N}^{\circ} 32$, Mercedes, octubre de 1998, p. 14.

12 Véase "Centro Histórico y Geográfico de Soriano, 40 años Irradiando Cultura a Través del Pasado Regional”, Revista Histórica de Soriano, Mercedes, №32, octubre de 1998, p. 1.
} 
sido donadas para formar un museo regional y ahora son conservadas y exhibidas en el Centro. En ese sentido, cabe señalar que los entrevistados nos comentaron el interés por vincularse al Sistema Nacional de Museos, proceso que se encuentra en trámite.

Actualmente el acervo del Centro incluye registros de propiedades desde 1878; el archivo de la Junta Económico Administrativa, que fue recuperado del Corralón Municipal antes de ser remitido a la Papelera Mercedes para transformarse nuevamente en papel; la biblioteca del Club Progreso de Mercedes, el primer club progresista del país.

Recientemente se ha abierto al público la biblioteca del profesor Manuel Santos Pírez, donada enteramente por sus familiares. Se destaca particularmente una maqueta que representa a la ciudad de Mercedes en 1834 (Villa Soriano), realizada por varios integrantes del CHGS, entre ellos Alfonso Arias, en ocasión del bicentenario de la ciudad en 1988. Esta es constantemente visitada, tanto por instituciones

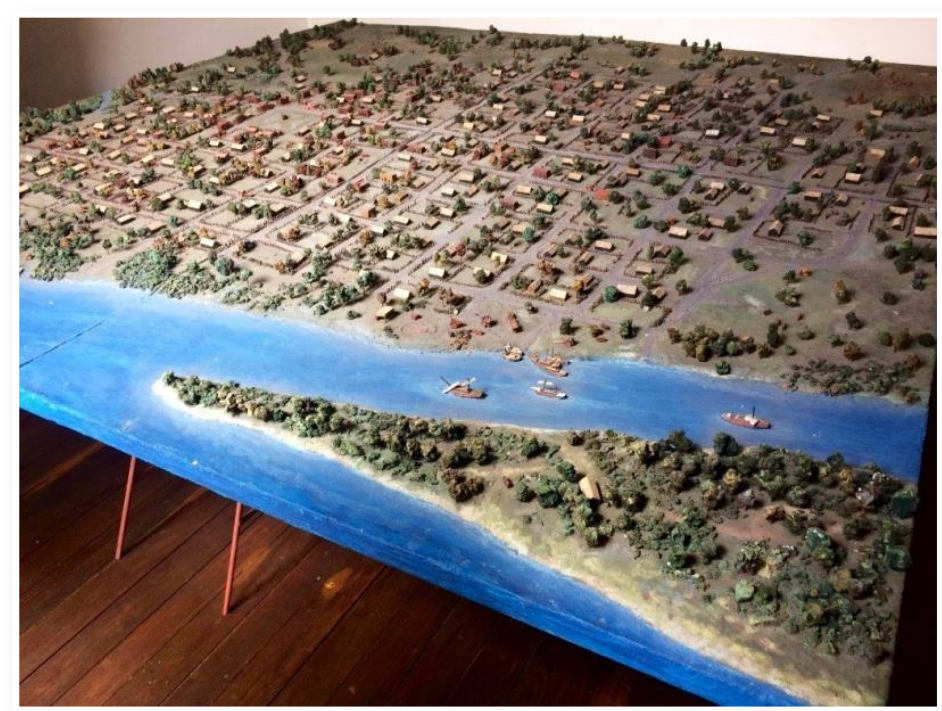

Maqueta que representa la ciudad de Mercedes en 1834. Realizada por el Centro Histórico y Geográfico de Soriano en 1988. educativas como por particulares.

La vinculación de la mayor parte de sus integrantes con la educación secundaria generó rápidamente un interés por la difusión de sus trabajos a un público amplio. Los libros realizados desde el Centro generalmente tienen buena repercusión en de la sociedad mercedaria. En su mayoría no son comercializados, sino que son repartidos en instituciones educativas o son vendidos a precios simbólicos. También realizaron discos compactos que contienen todos los números de la Revista Histórica de Soriano en formato digital. 
En la actualidad el principal órgano de difusión del CHGS es el Boletín digital, donde se divulgan notas históricas relacionadas con el departamento y se da cuenta de lo realizado por la institución. A su vez, desarrollan un blog que, además de

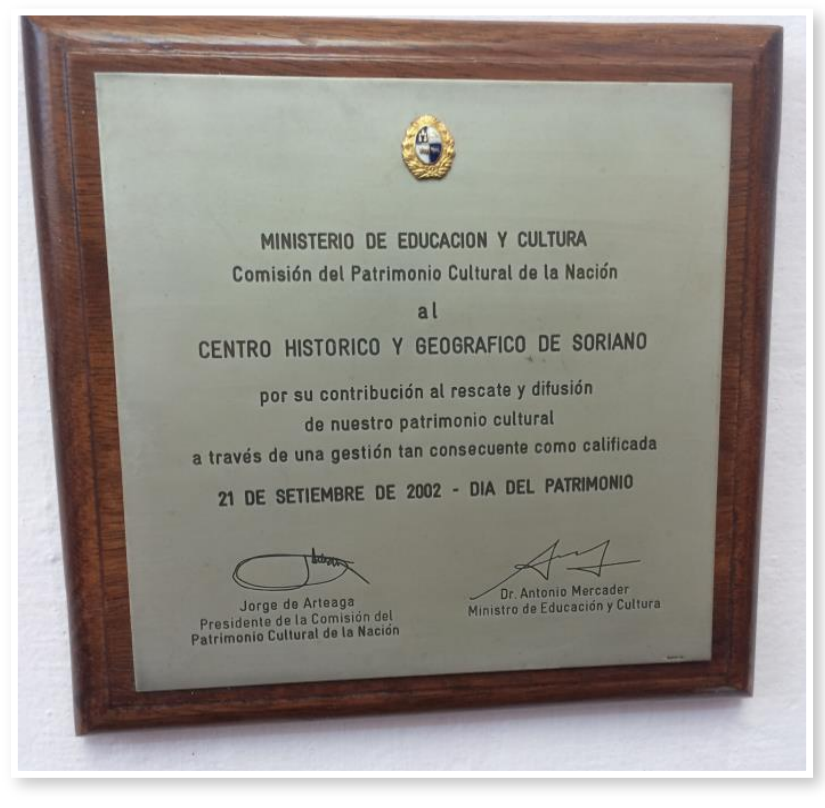

Placa otorgada por la Comisión del Patrimonio Cultural de la Nación, Ministerio de Educación y Cultura, en 2002. información sobre el Centro, pone en acceso público documentos digitalizados relacionados con la historia de Soriano ${ }^{13}$.

En estos sesenta años el Centro Histórico y Geográfico de Soriano ha congregado a aficionados, docentes e investigadores preocupados por el cultivo de la Historia, la Geografía y otras disciplinas relacionadas y ha sido promotor de diversos proyectos relacionados con la historia del departamento.

En estas seis décadas de trabajo la institución se ha ganado un lugar como referente en la ciudad y un reconocimiento, no solamente a nivel local, sino nacional y regional. El gran desafío hacia el futuro es acercarse a las nuevas generaciones para que continúen y enriquezcan el camino trazado.

En sus propias palabras, "el Centro Histórico y Geográfico de Soriano rescata, revaloriza y expone el pasado de Soriano, como base y sostén del mañana que hoy construimos y que también un día será Historia” ${ }^{4}$. 


\section{Entrevista a Alfonso Arias, investigador y directivo del CHGS}

A continuación transcribimos algunos fragmentos de la extensa entrevista que realizamos el 4 de diciembre de 2017 a uno de los principales exponentes de la Historia sorianense e integrante de la Comisión Directiva del Centro Histórico y Geográfico de Soriano, escribano Alfonso Arias. Nos abrió las puertas de su casa para conversar sobre su vinculación a la Historia como disciplina, su acercamiento al quehacer histórico y a la actividad del Centro y su convicción sobre la necesidad de hacer Historia local.

\section{¿Cómo fue su vinculación inicial con la Historia? Sus primeros intereses, ¿a qué se debieron?}

Aunque parezca mentira, me decían, yo no me acuerdo, que cuando me levantaba para ir a la escuela, ponía el libro de historia en el lavatorio, atrás de la canilla y me lavaba la cara mirando y leyendo historia. Historia de la época de los antiguos, de Grecia, de Roma, que me gustaba en ese momento, cuando iba a la escuela. Tal vez de ahí viene el gusto por la historia.

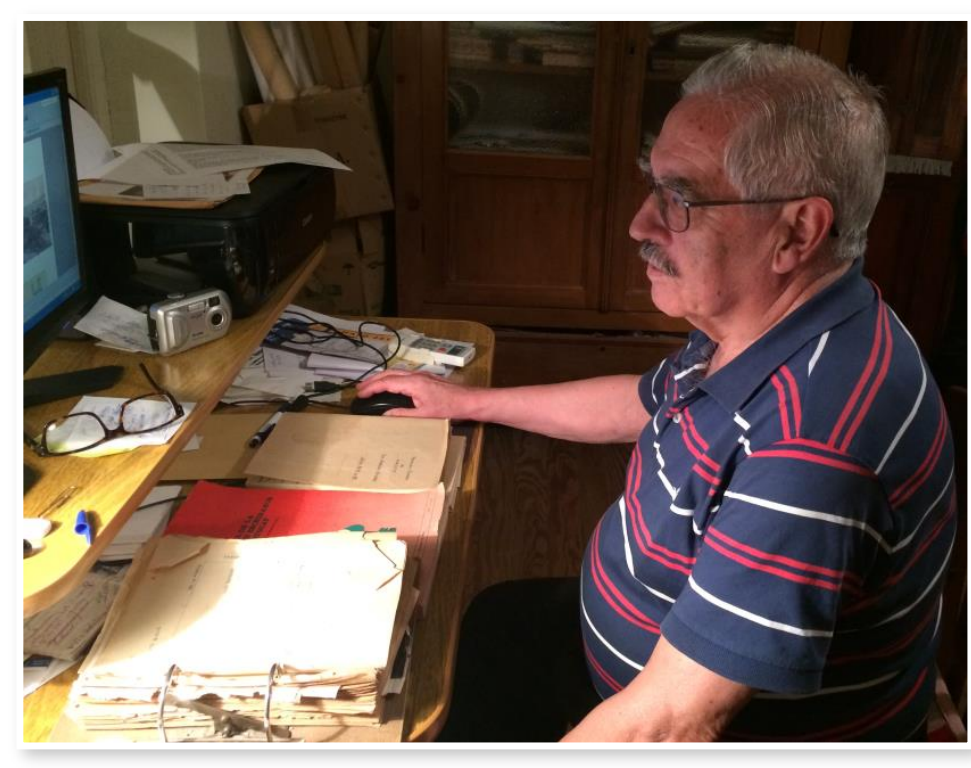

Alfonso Arias en su estudio, ciudad de Mercedes, Soriano. 4 de diciembre de 2017.

\section{¿Su formación es de escribano?}

Mirá, yo he hecho de todo un poco. Trabajé en el banco La Caja Obrera veintidós años. Mientras trabajaba estudié y después, sí, treinta años de trabajo como escribano. Cuando me jubilé, de 63 años [que tenía], había trabajado 55. Acumulando los periodos.

\section{¿Siempre en el banco y después como escribano?}


Sí, pero fueron simultáneos también. Me fui a Montevideo, siguiendo los cursos normales y allá entré en el banco mientras estudiaba. Me entusiasmé con lo que se ganaba como bancario, y después dije "me voy a Mercedes", y me vine. Dejé de estudiar estando en tercero de escribanía y seguí trabajando acá en la parte bancaria. Me casé, ya teníamos dos hijos cuando, en determinado momento, me volvió el interés por seguir la carrera. Volví a Montevideo después de diez años, y terminé la carrera allá. Siempre trabajando en el banco. Vine de nuevo, ya recibido, y seguí trabajando en el banco juntamente con el trabajo de escribano. $Y$ después de siete años dejé el banco y me dediqué al notariado.

\section{¿En qué año se recibió de escribano?}

En 1972.

\section{¿Por esos años fue que tuvo los primeros contactos con el Centro Histórico?, ¿conocía a alguno de los del grupo inicial?}

Sí, pero el asunto también venía por otro lado. A mí siempre me gustó el ciclismo, corría carreras de bicicletas y estaba relacionado con la Federación Ciclista de Soriano. En ese entonces estaba como presidente el profesor Eduardo Galagorri, quien fue varios años presidente de la Federación. Yo hacía notas en los diarios relatando las carreras de ciclismo y a través de él, que ya estaba en el Centro Histórico, empecé a conectarme; él fue quien me acercó.

\section{La revista Soriano Actualidad, ies de los sesenta?}

$\mathrm{Si}$, en esos años ya me había vuelto de Montevideo y vi que prácticamente no existían más que algunos diarios. Entonces me interesé por darle otro conocimiento al vecindario de todo lo que estaba pasando. Por eso empezamos a realizar esa revista Soriano Actualidad, junto a un muchacho, Fortunato Ritorni, quien era el otro redactor responsable. Él también estaba relacionado con el ciclismo y transmitíamos por la radio las carreras de bicicleta. Entonces todo eso se fue juntando y fue lo que nos motivó a hacer la revista. Detallábamos la parte social, la parte deportiva, de todo un poco. Era una manera de mostrarle a la gente lo que había en la ciudad y en el departamento.

Y de ahí, al Centro Histórico de Soriano... 
Bueno, en esos años también empezó el interés por las notas de Lockhart y las de Santos Pírez, que llamaban siempre la atención. Y bueno, me gustó y empecé a leerlas, a coleccionar algunas y de a poco, a hacer algo yo también.

\section{Le parece que su carrera, su formación como escribano, ¿le ayudó} en sus investigaciones?

Sí, posteriormente sí. Me hizo interesar más por la parte histórica. La prueba está en que ya en el año 1980 publiqué en la Revista de la Asociación de Escribanos del Uruguay un trabajo con las biografías de los escribanos que actuaron en el departamento de Soriano desde 1925 hasta ese momento. Accedí a los protocolos de los antiguos escribanos del departamento; y eso mismo fue impulsando todo lo demás. Vas conectando una cosa con la otra y ahí también interviene la parte geográfica, que siempre se relaciona con lo del Centro Histórico.

En los primeros años de vida del Centro, los documentos con los que empezaron a trabajar, ¿estaban en Soriano o tenían que ir a buscarlos a Montevideo?

En esa época, por ejemplo, los del juzgado estaban acá y después los llevaron a Montevideo. [Washington] Lockhart y Manuel [Santos Pirez], también Telésforo [Book] y Glauco Cabrera, todos ellos consultaron esos documentos. Incluso, yo también pude hacerlo, pero después vino una orden y ahora todo se centra allá en el Archivo Judicial [AGN]. En un principio marchó todo en bolsas, entonces hubo un interregno que no se podía consultar ni acá ni allá. No me acuerdo bien el año, pero eso dificultó mucho el poder trabajar y algunas cosas quedaron en el limbo, o iniciadas y que nunca se terminaron.

Yo trabajé mucho con los protocolos de los escribanos, esos sí quedaron en el juzgado acá y están en cada lugar, en su sitio digamos. Con esos documentos trabajé mucho, porque en determinado momento me los facilitaban- Pero también está el problema de que cambian las autoridades y no puedes sacar una cosa u otra. A veces se dificulta, porque tampoco podés pasarte todo un día sentado ahí sacando anotaciones.

El interés por la historia genealógica, ¿se debió a una motivación personal o lo entendió como una necesidad para la historia de la ciudad o el departamento? 
En principio influyó mucho la lectura de Génesis de la familia uruguaya de Juan Alejandro Apolant. Ahí trataba muchas cosas y había mucho relacionado con Soriano y con personajes de la zona. Todo eso me hizo interesar por la parte genealógica. Fuera de eso, después con Santos Pírez nos contactamos mucho con las instituciones genealógicas de otros lugares.

\section{¿Con Apolant llegaron a tener algún contacto?}

Lamentablemente con él directamente no, porque falleció antes. Con la señora y la hija sí. Pero el trabajo de él es admirable. Una persona que no era uruguayo, no era de la zona, interesarse de esa manera y haber obtenido toda esa información, es impresionante.

Con respecto a las investigaciones, ¿cómo es la respuesta de la comunidad?, ila gente se interesa por su trabajo?

La parte histórica concita interés, la parte genealógica tiene dificultades. No sé si acá a la gente no le gusta o le choca un poco el hecho de que se busquen los ancestros, que se ande buscando de dónde venimos.

Acá, en general, la gente es bastante reacia. en ese aspecto, pero no quiere decir que actualmente algunas personas y de forma individual no se preocupen. Porque una vez que buscas un dato o dos de tu familia, ya después no te desprendes más de eso. Seguís buscando y revolviendo hasta llegar a quién sabe dónde. Porque generalmente muchas personas se van de la ciudad y después pierden contacto totalmente. Luego de una o dos generaciones empiezan a interesarse por los orígenes familiares y eso hace que nos contacten buscando datos.

\section{Y con las otras obras de tipo histórico, ¿ha notado que la gente se interesa?}

$\mathrm{Si}$, sobre todo las últimas, que son recopilaciones de esas notas que yo saco en el diario Crónicas todas las semanas. El problema es que cuando la gente se interesa, se interesa por la nota 32, por ejemplo, pero le faltan todas las anteriores. Entonces, esta es una manera de que tengan todo junto, a través de esos libros como Ayer y hoy, que publiqué el año pasado [2016]. Docentes de primaria y secundaria los buscan mucho, se usan en centros educativos.

\section{¿Tiene alguna idea de cuántos trabajos ha publicado?}


Tengo una lista acá de los libros y de las revistas, salvo las notas que salen todas las semanas. También escribí mucho en Entrega 200o, otra publicación que salía hasta hace poco, que era semanal. Como redactor responsable de la Revista Histórica de Soriano durante varios años, publiqué mucho. Ahora estamos haciendo el Boletín digital con Agustín Listur.

También está la maqueta de la ciudad de Mercedes en 1834. Es visitada permanentemente por grupos de escuelas, de liceos, de la UTU; de todos lados vienen visitantes y turistas. En fin, siempre llama la atención. Va a cumplir treinta años y ha habido gente que fue con la escuela a los tres o cuatro años de estar hecha y vuelven ya grandes, con hijos inclusive, y se acuerdan de cuando vinieron y lo que les representó.

\section{La maqueta está hecha a escala, o sea con toda la rigurosidad...}

No solamente a escala, está hecha con los relieves de la ciudad, porque uno de los muchachos que trabajó era ayudante de arquitecto, entonces la hizo con la caída que tenía en determinados lugares. No es una cosa horizontal.

\section{¿Actualmente en qué está trabajando?}

Ahora en las notas semanales del diario, lo demás está quieto.

\section{A grandes rasgos, ¿sobre qué hablan las notas?}

Recordando cosas que han pasado a través del tiempo, cuándo se hizo tal edificio o tal institución. Recordando las fechas, algún elemento que interese; también algún hecho policial. Digamos, volver a repetir la vida de otra época, para la gente que está viviendo ahora, que no sabe lo que pasó.

¿Cómo selecciona los temas para estos artículos del periódico?, ¿hace una lista mensual?

$\mathrm{Si}$, voy buscando. Por ejemplo, ahora estaba con el año 1947 y estoy haciendo 1950. Voy sacando datos y después lo completo con las fotos.

Esas fotos, ¿dónde las consigue?, ¿̇están en el Centro? 
Bueno, eso es lo que da más trabajo. Tratar de adecuar... Hay de todo, están en el Centro, yo tengo muchas o busco en las revistas, sacando de algunas anteriores. Porque ha habido muchas publicaciones acá de otro tipo, publicaciones deportivas o de partidos políticos; entonces algunas de esas yo las tomo y las presento ahí.

El primer contacto que tuvimos con su trabajo fue el libro La Capilla Nueva de Mercedes, que es un trabajo también a pulmón...

Se basó en un censo, que fue publicado más de una vez en la revista del Centro Histórico, pero hablaba solamente de los nombres y nada más. Entonces empecé a investigar sobre cada nombre, con partidas, buscando datos, después buscando a los hijos y todo lo demás. Y a raíz de eso redondeé el libro y los siguientes, como El éxodo en Soriano, que nunca había sido estudiado desde ese lado. Busqué las familias de Soriano que habían participado, me puse a ver y después las relacioné con la parte genealógica.

[En su oficina, Alfonso Arias tiene un fichero con información sobre las trayectorias de vida de las personas que ha estudiado, con los datos que ha encontrado sobre ellos y los documentos donde se encuentran esos datos.] ¿Esto cómo lo hacía?, ientrecruzamiento de fuentes y registros a mano?

Claro, porque en esa época yo no manejaba la computadora para nada (en realidad la empecé a dominar después que me jubilé). Y bueno, son censos y censos... iba poniendo la información de cada persona en fichas a medida que iban surgiendo los datos.

Les voy a mostrar otro trabajo, que está relacionado con la maqueta. [Exhibe un cuaderno con información de propietarios de cada manzana, organizados por año]. La maqueta tiene veinte manzanas. Con esas veinte manzanas yo trabajé haciendo la sucesión de propietarios, manzana por manzana. Lo fui llevando a años posteriores hasta 1940. Para trabajar con esto, me basaba en los protocolos del registro de traslaciones de dominio. Que a su vez los tengo casi todos copiados y todas las operaciones que están registradas. Después lo pasaba a los planitos e iba ubicando a qué manzana correspondía cada uno. Algunos no los ubiqué porque no tenía la información para saber de qué manzana era. Hay que tener tiempo, ganas y pensar un poquito...

$-00000$ 